\title{
Teatro na escola com ou sem partido sempre será político
}

\section{Theater in school with or without a party will always be political}

Fernando Bueno Catelan ${ }^{1}$

Carminda Mendes André2 


\section{Resumo}

No Brasil, nos últimos anos, projetos de lei baseados no movimento "escola sem partido" tem sido criados e discutidos em casas legislativas objetivando promover uma educação "neutra" nas escolas e proibir quaisquer conteúdos que abordem posições político-partidárias. No entanto, essas propostas se mostram tendenciosas em suas tentativas de proibir conversas sobre política. Algo que pode ser considerado impossível, uma vez que a política está presente em todas as nossas relações coletivas, inclusive nas escolas. Nesse artigo, observamos aspectos políticos intrínsecos ao fazer escolar e teatral. Tomando como base os estudos de Rancière sobre "a política".

Palavras-chave: Política; escola sem partido; Teatro do Oprimido

\section{Abstract}

In Brazil, in recent years, bills based on the movement "school without a party" have been created and discussed in legislative houses to promote "neutral" education in schools and to ban any content that addresses political-party positions. However, these proposals are biased in their attempts to prohibit conversations on politics. Something that can be considered impossible, since politics is present in all our collective relations, including in schools. In this article, we observe political aspects intrinsic to school and theatrical doing. Based on Rancière's studies on "politics".

Keywords: Politics; school without party; Theater of the Oppressed

E-ISSN: 2358.6958

\footnotetext{
1 Ator, Educador, Pesquisador, Diretor Teatral e lluminador. Mestre em Artes pelo Instituto de Artes da Universidade Estadual Paulista "Júlio de Mesquita Filho" UNESP/ São Paulo. fernandocatelan@yahoo.com.br

2 Profa. Dra. Programa de Pós-Graduação em Arte do Instituto de Artes da Universidade Estadual Paulista - UNESP. Coordenadora do Grupo de Pesquisa Performatividades e Pedagogias Cnpq. Coordenadora da Instituição Promotora do DINTER entre UNESP e UFT. carminda.stenio@uol.com.br
} 
Vivemos tempos difíceis. A liberdade de cátedra ou liberdade acadêmica está sendo ameaçada, mesmo que já tenha sido garantida no artigo 206 de nossa Constituição Federal de 1988, que apresenta os princípios-base para o ensino: "II - liberdade de aprender, ensinar, pesquisar e divulgar o pensamento, a arte e o saber; III - pluralismo de ideias e de concepções pedagógicas, e coexistência de instituições públicas e privadas de ensino [...]" (Brasil, 1988).

A defesa das liberdades de modo geral e em especial na escola, deve ser nossa bandeira. A ameaça de sanções e punições a professores e professoras que ousarem falar sobre política em suas aulas é real e já acontece em casos de profissionais da educação constrangidos e ameaçados por denúncias de alunos, alunas e políticos ${ }^{3}$. Isso tudo embalado por um movimento que se autodenomina "escola sem partido", que tem como um de seus defensores o candidato eleito presidente do país, em 2018, Jair Messias Bolsonaro.

O movimento "escola sem partido" é uma ação política junto ao poder legislativo para tornar lei uma série de medidas que "proíbe" em sala de aula a manifestação de ideias "partidárias". Ao inserir a palavra "partido" no nome do projeto, nos remete apenas, em um primeiro momento, a partidos políticos, nesse sentido parece ser interessante, uma vez que é unânime que não queremos uma educação partidarizada, no sentido de organização de partidos políticos. Porem a expressão "partido" do projeto não é somente em relação aos partidos, mas também em "tomar partido" sobre algo. Para eles, o ensino deve ser neutro e o processo de ensino-aprendizagem também, o que é impossível como veremos mais adiante.

Porém, se analisarmos mais cuidadosamente as propostas e o histórico de intencionalidades da "escola sem partido", vamos perceber que o que se intenciona é apenas proibir uma única linha de pensamento político que, por eles, é associada aos partidos de esquerda.

A trajetória do movimento "escola sem partido" é bastante obscura. Não dispomos de informações precisas sobre sua fundação, as pessoas que o integram, nem as motivações que levaram ao surgimento dessa iniciativa. $O$ único nome que aparece no site (www.escolasemparido.org) dessa organização é o de seu coordenador, Miguel Francisco Urbano Nagib, e a primeira data de registro é de 2004.

Daniele Brait, em seu texto Os protagonistas do ESP, do livro A ideologia do movimento escola sem partido (in: Ação Educativa, 2016), nos apresenta um breve histórico do movimento. Ela destaca que há poucas informações do movimento de 2004 a 2014. A "escola sem partido" começa a ficar conhecida em 2014, com as ações de projetos de leis apresentados nas casas legislativas.

No Rio de Janeiro: PL 2974/20014 (estadual) e PL 867/2014 (municipal), ambos apresentados pelos filhos de Jair Bolsonaro. Em âmbito nacional, também em 2014 foi apresentado o PL 7180/2014, pelo deputado federal Erivelton Santana (PS-

\footnotetext{
3 Como os casos do professor Pedro Mara, da rede estadual do Rio de Janeiro, que foi denunciado, por apologia a drogas, pelo deputado estadual (RJ) Flavio Bolsonaro (PSC), que acionou o Ministério Público para pedir a exoneração do professor. Também professora Rosângela Rehermann de Uruguaiana (RS), denunciada pelo vereador Eric Lins Gripo (DEM), por fazer doutrinação aos alunos e alunas, após isso, a docente foi convidada a ir para outra escola. Na cidade de São Paulo o professor Thiago de Souza Lima, pediu demissão da escola particular de ensino fundamental e médio que lecionava, depois de ser chamado de radical por ter incentivado os alunos e alunas a realizarem assembleias para discutir seus problemas. Na Universidade Federal do Rio Grande do Sul a professora Natalia Pietra Mendez do Departamento de História, foi ameaçada em suas redes sociais e teve sua vida pessoal exposta na internet, ao ser acusada de fazer apologia ao estupro. Informação disponível em <http://www.cartaeducacao.com.br/reportagens/escola-sem-partido-intimida-e-persegue-professores/>. Acesso em: 23 fev. 2019.
} 
C-BA), e depois anexado a esse projeto o PL 867/2015, do deputado Izalci Lucas Ferreira (PSDB-DF). O pastor senador Magno Malta (PR-ES) apresentou no senado o PL 193/2016.

Claramente, os políticos apoiadores de: "escola sem partido" seguem a mesma corrente ideológica, portanto, há clara intencionalidade política partidária: "Nas eleições municipais de 2016, uma página do Facebook anunciava os candidatos a vereador pelo Escola Sem Partido. Lá estavam candidatos de vários partidos: PMDB, PSDB, PMN, PSC, DEM, Solidariedade, PPL, PRTB, PP, PTN e PV" (BRAIT. in: AÇÃO EDUCATIVA (Org.), 2016, p. 164).

Quantidade de projetos de deputados (federais e estaduais) e vereadores inspirados no ESP

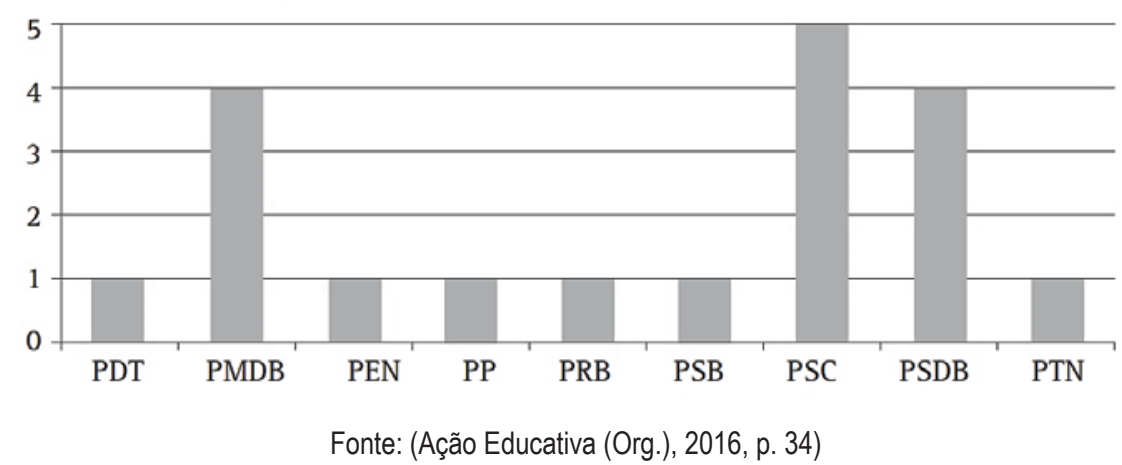

Em maio de 2016, o projeto "escola livre" é aprovado no Estado de Alagoas sob a Lei no 7.800. Nesse projeto, fica explícita a intenção de "escola sem partido", pois em seu Art. $2^{\circ}$ a censura é estendida à manifestação política. Contudo, como veremos a seguir, essa proibição não é possível, pois política são todas as ações dos sujeitos que vivem em comunidade.

Art. $2^{\circ}$ São vedadas, em sala de aula, no âmbito do ensino regular no Estado de Alagoas, a prática de doutrinação política e ideológica, bem como quaisquer outras condutas por parte do corpo docente ou da administração escolar que imponham ou induzam aos alunos opiniões político-partidárias, religiosa ou filosófica. (Alagoas, 2016)

Em 2017, o ministro Luís Roberto Barroso, do Supremo Tribunal Federal (STF), julgou inconstitucional a Lei 7.800/2016 do estado de Alagoas ${ }^{4}$ e emitiu medida cautelar contra a lei, que fora baseada no programa "escola sem partido". Porém, mesmo após essa derrota, no congresso nacional o projeto da "escola sem partido" (PL 7180/14), ainda tramita na Câmara Federal, agora com modificações.

O deputado federal Flavinho (PSC-SP), após o TSF ter declarado inconstitucional a lei "escola livre" de Alagoas, apresentou um substitutivo retirando a redação anterior da lei da chamada "escola sem partido" (PL 7180/14) e, propondo um novo texto, que prevê nas salas de aulas a obrigatoriedade da afixação de um cartaz com

\footnotetext{
4 Medida cautelar na Ação Direta de Inconstitucionalidade 5.537 Alagoas. Disponível em: <https://www.conjur.com.br/dl/liminar-suspende-lei-alagoas-criou.pdf>. Acesso em: 29 out. 2018.
} 
seis "deveres" do professor". Cartaz que é apresentado no site do programa escola sem partido:

\section{Deveres do professor}

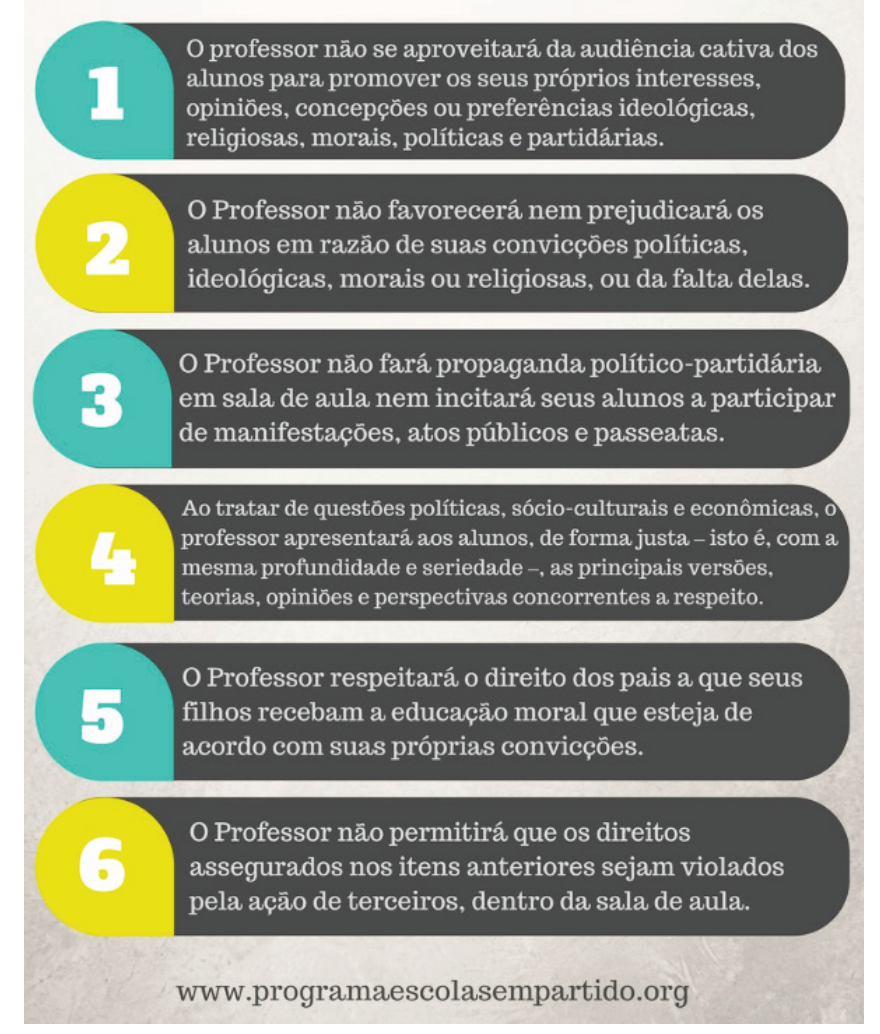

Fonte: Site Escola Sem Partido (https://www.programaescolasempartido.org/)

Cabe destacarmos que a censura não se restringe apenas a professores e professoras, como descrito no item 1 do cartaz, mas também é vedado aos alunos e alunas manifestarem ideias, conforme item 6 , sendo possível que professores e professoras denunciem os alunos e as alunas e vice-versa. Ou seja, a censura instaura um estado policialesco, como veremos, pois, toda vez em que não há a prática da política (no sentido de manifestação de pensamento que organiza a convivência coletiva) temos a polícia (que impõe a organização da sociedade por meio da força).

Pode parecer absurdo que essa Lei venha a ser aprovada ${ }^{6}$, em âmbito federal, uma vez que o Ministro Barroso já a declarou inconstitucional. No entanto, no atual cenário da política brasileira, o absurdo pode vir a ser considerado legal.

Cabe-nos analisar as intencionalidades da proposta e apresentar a quão absurda ela é, uma vez que tem suposta legitimidade ao se apresentar como "escola sem partido". O que a torna em si mesma contraditória, pois a Lei e seus defensores têm posição declaradamente político-partidária. Por isso, fica evidente que há intenção

\footnotetext{
5 Disponivel em: <http://www2.camara.leg.br/camaranoticias/radio/materias/RADIOAGENCIA/557030-RELATOR-DO-PROJETO-ESCOLA-SEM-PARTIDO-PROPOE-CARTAZ-EM-SALA-DE-AULA-COM-DEVERES-DO-PROFESSOR.html>. Acesso em: 29 out. 2018.

${ }^{6}$ Esse artigo está sendo es crito no final do mês de outubro de 2018, e é provável que leitores e leitoras que o lerão posteriormente já saibam da aprovação ou não do projeto.
} 
de se perseguir apenas uma forma de pensamento político: aquela que vai contra a ideologia política dos que a defendem.

A nós compete destacar o caráter político da educação e o do teatro, pois conforme explicitou Augusto Boal, em 1974, em seu primeiro livro, Teatro do Oprimido: e outras poéticas políticas: "Este livro procura mostrar que todo teatro é necessariamente político, porque políticas são todas as atividades do homem, e o teatro é uma delas" (2013, p. 13).

Boal, ao afirmar que todas as ações dos seres humanos são políticas, nos diz que não há neutralidade no teatro ou na educação, e que se dizer imparcial é uma estratégia para agir na direção política de quem diz isso. "Os que pretendem separar o teatro da política pretendem conduzir-nos ao erro - e essa é uma atitude política" (BOAL, 2013, p. 13), como podemos observar nas intencionalidades da "escola sem partido":

A doutrinação política e ideológica em sala de aula ofende a liberdade de consciência do estudante; afronta o princípio da neutralidade política e ideológica do Estado; e ameaça o próprio regime democrático, na medida em que instrumentaliza o sistema de ensino com o objetivo de desequilibrar o jogo político em favor de um dos competidores. [...].

Essas práticas, todavia, apesar de sua manifesta inconstitucionalidade e ilegalidade, tomaram conta do sistema de ensino. A pretexto de 'construir uma sociedade mais justa' ou de 'combater o preconceito', professores de todos os níveis vêm utilizando o tempo precioso de suas aulas para "fazer a cabeça" dos alunos sobre questões de natureza político-partidária, ideológica e moral. (Escola sem Partido, 2018; grifo nosso)

Entender que o ensino pode ser isento de intencionalidades é ignorar o que vem a ser a política em sua essência. A política é o ato de falar e de se manifestar. E apenas numa prática educativa que permita a manifestação de todos e todas é que podemos diminuir as opressões que o próprio sistema de ensino tradicional impõe, ao dizer que quem fala é o professor e por isso ele é o detentor "único" do conhecimento, e assim deposita seu conhecimento na cabeça dos alunos, como nos explica Paulo Freire ao chamar essa metodologia de ensino tradicional de "Educação Bancária" (2015, p. 79-106).

É interessante e contraditório o fato de o movimento "escola sem partido" criticar professores e professoras, como se eles pudessem abusar de seu uso de fala, ao mesmo tempo em que defende que o sistema continue o mesmo, ou seja, que apenas professores e professoras possam falar, e que a participação de alunos e alunas não deva ser estimuladas para que a participação democrática se efetive.

No site do movimento "escola sem partido" temos uma citação de Max Weber (sem a indicação bibliográfica) criticando a possibilidade de abuso da "audiência cativa" que professores e professoras detêm.

Em uma sala de aula, a palavra é do professor, e os estudantes estão condenados ao silêncio. Impõem as circunstâncias que os alunos sejam obrigados a seguir os cursos de um professor, tendo em vista a futura carreira; e que ninguém dos presentes a uma sala de aula possa criticar o mestre. É imperdoável a um professor valer-se dessa situação para buscar incutir em seus discípulos as suas próprias concepções políticas, em vez de lhes ser útil, como é de seu dever, através da transmissão de conhecimento e de experiência científica. (Weber apud Escola sem Partido, 2018) 
Se o problema fosse essa hipótese de o professor e a professora "abusarem" de sua autoridade por meio do uso da fala na sala de aula, não seria mais coerente a "escola sem partido" estimular a participação de todos e todas e assim defender a política, que é a manifestação das ideias? Bem, essa não é a questão para eles, pois a intencionalidade, por trás do movimento, consiste em defender suas posições ideológico-partidárias, censurando os contrários às suas ideologias e assim neutralizando a pluralidade de pensamento.

E é apenas por meio de um ensino realmente crítico que podemos pressupor uma escola que dialogue com as múltiplas posições políticas. Para isso, é preciso que a palavra circule livremente nas aulas. Contudo, antes precisamos nos entender como iguais em inteligência, elemento essencial para uma atitude política.

Rancière (1971), ao romper com seu mentor Louis Althusser após os acontecimentos de maio de 1968, em Paris, por posicionamentos políticos divergentes, mergulha na pesquisa da vida cotidiana dos operários (1988) e conclui que, se almejamos uma ação política para a transformação da sociedade, é necessário partirmos da ideia de que todos somos iguais em inteligência, sendo, portanto, a igualdade o ponto de partida para a ação política.

É nessa aproximação da vida cotidiana dos operários franceses do século XIX que Rancière conhece as propostas pedagógicas de Jacotot, sobre quem escreve um livro dedicado exclusivamente a sua metodologia de ensino: O mestre ignorante (2011). E é nesse ponto que a política e a educação são colocadas lado a lado, na mesma direção conforme fez Paulo Freire.

Rancière entende a igualdade como elemento essencial para a política. Apenas nos sentimos à vontade para dizer o que pensamos se não acharmos que somos inferiores a quem nos escuta. Saber que somos iguais em inteligência nos permite a liberdade da manifestação. Ao escutar uma pessoa, percebemos que entendemos o que ouvimos e que somos igualmente inteligentes, por isso podemos nos sentir livres para dizer algo a respeito do que está sendo conversado. É isso que é a política: a possibilidade de que no ato de manifestação de ideias todos e todas possam dizer o que pensam.

Porém, a política é anárquica. A política traz o dissenso, uma vez que a multiplicidade das manifestações pode ser percebida como sendo o caos. De outro lado, "O consenso é a redução da política à polícia, isto é, não o cumprimento dos seus fins, mas simplesmente o retorno do estado normal das coisas, que é o da sua não existência" (Rancière, 2014, 153). Por isso, a "escola sem partido" não admite a expressão e o pensamento político. É um movimento contra a pluralidade de ideias, visto que não exercitar a política permitiria a manipulação para a sua corrente ideológica.

Rancière é claro ao dizer que há oposição entre a política é a polícia. E é esse estado policialesco, de vigilância e repressão, estimulado pelos partidários do "escola sem partido", quando incitam alunos e alunas a gravarem, filmar e denunciar seus professores e professoras ${ }^{7}$. Nesse caso, as artes na escola representam um dos focos

\footnotetext{
7 Exemplo da deputada estadual Ana Caroline Campagnolo (PSL), eleita em 2018 pelo estado de Santa Catarina, que pediu aos estudantes que denunciem seus professores "doutrinadores", conforme reportagem do Jornal Folha de São Paulo, de 29 de outubro de 2018. Disponivel em: <https://www1.folha.uol.com.br/ poder/2018/10/deputada-eleita-do-psl-pede-que-estudantes-denunciem-professores-contra-bolsonaro-em-sala-de-aula.shtml>. Acesso em: 02 nov. 2018.
} 
mais atingidos, pois não há arte sem liberdade e sem política: "a arte é em si mesma o meio da formação de uma verdadeira liberdade política da humanidade" (Guinsburg; Koudela, 1992, p. 23).

E é necessário, se intencionarmos uma educação transformadora das opressões, que a arte possa ser trabalhada destacando seu caráter político ao abrir espaço para a livre manifestação, uma vez que os oprimidos são "cidadãos aos quais se subtraiu o direito à palavra, ao diálogo, ao seu território, à sua livre expressão, à sua liberdade de escolha" (Boal, 2009b, p. 173-174).

Precisamos cada vez mais estimular uma ação criadora nas escolas para que alunos e alunas sejam fazedores de arte, e não apenas receptores de arte: "É preciso primeiro que, os que assim se encontram negados no direito primordial de dizer a palavra, reconquistem esse direito, proibindo que este assalto desumanizante continue" (Freire, 2015, p. 109).

Segundo Boal, é importante que aqueles que se encontram na condição de oprimidos façam arte e não sejam apenas espectadores passivos, pois a arte pode vir a ser instrumento de manipulação dos interesses das classes dominantes: "O pensamento sensível é arma de poder - quem o tem em suas mãos, domina (...). Quando exercido pelos oprimidos, o Pensamento Sensível é censurado e proibido" (Boal, 2009a, p. 18).

Ao destacarmos que teatro e educação representam um ato político, defendemos a liberdade de expressão e o direito e a necessidade de termos arte na escola, para não permitir a manipulação do pensamento: "O analfabetismo estético, que assola até alfabetizados em leitura e escrita, é perigoso instrumento de dominação que permite aos opressores a subliminal Invasão dos Cérebros!" (Boal, 2009a, p. 15).

Por isso é necessário termos o entendimento de que fazemos teatro político na escola, e não ficarmos restritos ao considerar apenas político um teatro de militância (Garcia, 2004), que, obviamente, é político, mas o ato de se manifestar é político e é isso que, em essência é o teatro: ter algo a dizer a alguém.

Mesmo as manifestações teatrais que não são claramente de engajamento político, são políticas. Conforme afirma Denise Stoklos: "Todo teatro é político, se não é de esquerda é de direita"8. Assim, Teatro Político é mais do que um tipo de teatro "panfletário" (sem uso pejorativo dessa expressão), mas sim todo teatro é político, em todos os lugares, inclusive na escola.

A escola, por sua vez, oferece historicamente certa resistência ao ensino das artes, pois "A arte 'pensa' pela lógica da transgressão, ela é risco, dissolve, abala, nega" (André, 2007). E tudo que a escola busca é minimizar conflitos, harmonizar a convivência e criar um ambiente agradável, com o menor ruído possível. A defesa do ensino de arte na escola é uma ação política que se soma às intencionalidades de transformação da sociedade, que tanto almeja o espaço escolar.

Todavia, para que isso ocorra é preciso liberdade para se dizer o que se pensa, mesmo que essa liberdade seja ainda uma luta da área de artes dentro da própria escola.

Nesse momento, as diferenças com os que estão ao nosso lado representam o menor dos nossos problemas. Nosso inimigo é outro: o fascismo; o machismo; a

\footnotetext{
8 Fala Denise Stoklos proferida no Teatro João Caetano, na cidade de São Paulo, em 25 de novembro de 2002, durante a aula aberta: Solos do Brasil.
} 
LGBT-fóbica; o racismo; o fanatismo religioso. E infeliz ou felizmente, apresenta-se claramente em nossos dias: o que antes era escondido hoje está revelado. $O$ conservadorismo e o pensamento retrógrado sempre estiveram presentes na sociedade, mas agora estão escancarados.

Que venham as disputas no campo político! E que possamos respondê-las com arte, que é uma possibilidade de combater o retrocesso e a censura. "Não basta consumir cultura: é necessário produzi-la. Não basta gozar arte: necessário é ser artista! Não basta produzir ideias: necessário é transformá-las em atos sociais, concretos e continuados" (Boal, 2009a, p. 19).

\section{Referências}

AÇÃO EDUCATIVA. A ideologia do movimento Escola Sem Partido: 20 autores desmontam o discurso. São Paulo: Ação Educativa, 2016.

ALAGOAS. (BRASIL). Lei no 7.800, de 05 de maio de 2016. Institui, no âmbito do sistema estadual de ensino, o programa "escola livre". Disponível em: <http://sistemas. pm.al.gov.br/sistemas/public/sislegis/publico/download/id/169/param/2/set/2/get/ d2068f64/dist/1530109400>. Acesso em: 02 nov. 2018.

ANDRÉ, Carminda Mendes. Teatro e Cultura. In: IV Reunião Científica de Pesquisa e Pós-Graduação em Artes Cênicas, 2007, Belo Horizonte. Anais... IV Reunião Científica ABRACE, 2007, p. 259-252. Disponível em: <http://www.portalabrace.org/ivreuniao/GTs/Pedagogia/Teatro\%20 e\%20cultura\%20-\%20Carminda\%20Mendes\%20Andre.pdf>. Acesso em: 11 jun. 2016.

BOAL, Augusto. A estética do oprimido. Rio de Janeiro: Garamond, 2009a.

BOAL, Augusto. O teatro como arte marcial. Rio de Janeiro: Garamond, 2009b.

BOAL, Augusto. O Teatro do Oprimido e outras Políticas Poéticas. São Paulo: Cosac Naify, 2013.

BRAIT, Daniele. Os protagonistas do ESP. In: AÇÃO EDUCATIVA (Org). A ideologia do movimento Escola Sem Partido: 20 autores desmontam o discurso. São Paulo: Ação Educativa, 2016.

BRASIL. Constituição (1988). Constituição da República Federativa do Brasil, 1988. Brasília: Senado Federal; Centro Gráfico, 2013.

FREIRE, Paulo. Pedagogia do Oprimido. 59 ed. Rio de Janeiro: Paz e Terra, 2015.

GUINSBURG, Jacó; KOUDELA, Ingrid Dormien. Teatro da utopia: utopia do teatro? In: KOUDELA, Ingrid Dormien (Org). Um voo brechtiano: teoria e prática da peça didática. São Paulo: Perspectiva; FAPESP, 1992, p. 17-46. 
RANCIĖRE, Jacques. Sobre a Teoria da Ideologia - A Política de Althusser. Porto: Portucalense Editora, 1971.

RANCIÈRE, Jacques. A noite dos proletários - Arquivos do sonho operário. São Paulo: Companhia das Letras, 1988.

RANCIÈRE, Jacques. O desentendimento - política e filosofia. São Paulo: Editora 34, 1996.

RANCIÈRE, Jacques. O mestre ignorante. Belo Horizonte: Autêntica, 2011.

RANCIÈRE, Jacques. Nas margens do político. Lisboa: KKYM, 2014.

Recebido em: 13/11/2018

Aprovado em: 30/01/2019 